SLAC-PUB-7906

November, 1998

\title{
Characterization of Low-Energy (6-30 keV) Response of Polish TLDs (MTS-N, MCP-N) with Synchrotron Radiation and Determination of Some TLD Quantities·
}

\author{
N. E. Ipe, A. Fassò, K. R. Kase, R. Kaur, P. Bilski ${ }^{\dagger}$ and P. Olko ${ }^{\dagger}$ \\ Stanford Linear Accelerator Center, Stanford University, Stanford, CA 94070 \\ ${ }^{\dagger}$ Health Physics Lab, Institute Of Nuclear Physics, Krakow, Poland
}

Presented at the $12^{\text {th }}$ International Conference on Solid State Dosemetry

July 5-11, 1998

Burgos, Spain

Work supported by Department of Energy contract DE-AC03-76SF00515 
Abstract. Relative to ${ }^{137} \mathrm{Cs}$ gamma rays, the response of MTS-N ( ${ }^{\mathrm{Nat}} \mathrm{LiF}: \mathrm{Mg}, \mathrm{Ti}-0.04$ $\mathrm{cm}$ thick) increased from 0.4 to 1.4 between $\mathrm{x}$-ray energies of 6 and $30 \mathrm{keV}$ and that of MCP$\mathrm{N}$ ( ${ }^{\mathrm{Nat}} \mathrm{Lif}: \mathrm{Mg}, \mathrm{Cu}, \mathrm{P}-0.04 \mathrm{~cm}$ thick) increased from 0.02 to 1.2 between 6 and $26 \mathrm{keV}$. A mathematical model for TLD response was used with measured responses to determine overall TLD efficiency $\mathrm{C}(\mathrm{k})$ and efficiency relative to ${ }^{137} \mathrm{Cs}$. The effective energy attenuation coefficient $\mu(\mathrm{k})$ and light attenuation coefficient $\mathrm{f}$ were also determined experimentally. The relative efficiency of MTS-N increased from 0.66 to 1.30 between 6 and $30 \mathrm{keV}$ and that of MCP-N increased from 0.37 to 0.99 between 6 and $26 \mathrm{keV}$. 


\section{INTRODUCTION}

As new synchrotron radiation facilities are rapidly being constructed all over the world, they introduce the need for low-energy x-ray dosemeters because of the potential radiation exposure to experimenters who work in close proximity to the beam lines and experimental enclosures. However, they also serve as an important resource of monoenergetic x-rays that can be used for research and calibration of dosemeters. Low-energy x-rays are also useful in radiotherapy and radiodiagnostic techniques. For example, $17.5 \mathrm{keV}$ x-rays are used in mammography.

Most of the commercially available dosemeters are not designed to respond well to lowenergy $\mathrm{x}$-rays $(<30 \mathrm{keV})$ and frequently their responses at these low energies are not well known. Further, the holder or dosemeter packaging significantly attenuates the low-energy photons $(<10 \mathrm{keV})$. Hence, there is a critical need to develop a low-energy x-ray dosemeter. With this as the ultimate goal, a series of studies have been undertaken at the Stanford Synchrotron Radiation Laboratory (SSRL), in which the low-energy responses of thermoluminescent dosemeters (TLDs), are being determined using monochromatic xrays[1,2].

At the Solid State Dosimetry Conference in Budapest we reported our observations that the response of TLDs is not directly proportional to the energy deposited in the TLDs at photon energies below $17.5 \mathrm{keV}$ (1). This effect was attributed to the combined effect of attenuation of low-energy photons and attenuation of light in the TLD. In order to account for this effect, we applied a mathematical model to describe the TL response. This model can then be used with measured responses and values of light attenuation coefficient (f) and effective energy attenuation coefficient $(\mu(\mathrm{k}))$, to determine overall TLD efficiency $\mathrm{C}(\mathrm{k})$; and 
efficiency relative to ${ }^{137} \mathrm{Cs}$ (hereafter referred to as "relative" efficiency) as a function of photon energy $(\mathrm{k})$. The quantities $\mathrm{C}(\mathrm{k}), \mu(\mathrm{k})$ and $\mathrm{f}$ play a vital role in understanding basic $\mathrm{TL}$ mechanisms and in the modeling of TLD response. Both $\mu(\mathrm{k})$ and $\mathrm{f}$ can also be determined experimentally.

In order to model the response of the TLDs it is essential to use monoenergetic x-rays. Calibration facilities normally use fluorescent x-ray techniques or continuous spectra. In the latter case, filtration techniques are then made use of to generate "nearly" monoenergetic photon beams which have a spectrum with a peak at the desired energy. At synchrotron radiation $(\mathrm{SR})$ facilities one can choose any discrete energy, whereas there is a limited choice of energies available at calibration facilities. Finally, since synchrotron radiation beams are narrow collimated beams, they are very useful for measurements of fundamental TLD quantities such as $\mu(\mathrm{k})$ and $\mathrm{f}$.

In this paper we report the results of experiments to characterize the low-energy (6-30 $\mathrm{keV}$ ) response of the $0.04 \mathrm{~cm}-$ thick MTS-N ( $\left.{ }^{\mathrm{Nat}} \mathrm{LiF}: \mathrm{Mg}, \mathrm{Ti}\right)$ and MCP-N ( $\left.{ }^{\mathrm{Nat}} \mathrm{LiF}: \mathrm{Mg}, \mathrm{Cu}, \mathrm{P}\right)$ TLDs obtained from the Institute of Nuclear Physics, Poland. Both $\mu(\mathrm{k})$ and $\mathrm{f}$ were measured at a few energies. $\mathrm{C}(\mathrm{k})$ and relative efficiency were determined as a function of photon energy using calculated values of $\mu(\mathrm{k})$ and measured values of $\mathrm{f}$.

\section{THEORETICAL MODEL FOR RESPONSE OF TLD}

Under "ideal" narrow beam conditions, exponential attenuation (described by a linear attenuation coefficient $\mu$ ) will be observed for a monoenergetic beam of photons incident on a material. The photons are "ideal" in the sense that they are absorbed without producing 
scattered or secondary radiation. Real photon beams interact with matter producing both secondary and scattered radiation. Monte Carlo simulations show that the energy deposited per unit thickness, $\mathrm{dE} / \mathrm{dx}$ is exponentially distributed in the TLD along the beam direction $\mathrm{x}$ [2]:

$$
\frac{\mathrm{dE}(\mathrm{k})}{\mathrm{dx}}=\mathrm{N} \mu(\mathrm{k}) \mathrm{ke}^{-\mu \mathrm{x}}
$$

where $\mathrm{N}$ is the number of incident photons, $\mu(\mathrm{k})$ is an effective energy attenuation coefficient and $\mathrm{k}$ is the photon beam energy.

Assuming a simple exponential model also for light attenuation (which has been experimentally proved as described in Results and Discussions) and ignoring reflection of light from the planchet, an elemental layer of thickness $\mathrm{dx}$, located at a distance $\mathrm{x}$ from the face of the TLD, will contribute an amount $\mathrm{dR}$ to the response R. $\mathrm{dR}$ is proportional to the energy $d E=(d E / d x) d x$ deposited in that layer, weighted by a light attenuation coefficient $\mathrm{e}^{-\mathrm{fx}}$ :

$$
\mathrm{dR}(\mathrm{k})=\mathrm{C}(\mathrm{k}) \frac{\mathrm{dE}(\mathrm{k}) \mathrm{e}^{-\mathrm{fx}} \mathrm{dx}}{\mathrm{dx}}
$$

where $\mathrm{C}(\mathrm{k})=\eta \varepsilon$ is the overall TLD efficiency, $\eta$ is the intrinsic luminous efficiency (ratio of total energy emitted in the form of light to the energy absorbed in the TLD), and $\varepsilon$ is the reader efficiency which includes geometry dependence, sensitivity of the PM tube, etc; and f is the light attenuation coefficient of the TLD material.

Combining equations 1) and 2), we obtain, if the TLD is read out with the irradiated side facing the PM tube:

$$
\mathrm{dR}(\mathrm{k})=\mathrm{C}(\mathrm{k}) \mathrm{N} \mu(\mathrm{k}) \mathrm{ke}^{-[\mu(\mathrm{k})+\uparrow] \mathrm{x}} \mathrm{dx}
$$


Integrating over the whole TLD thickness $t$ results in:

$$
\mathrm{R}(\mathrm{k})=\frac{\mathrm{C}(\mathrm{k}) \mathrm{N} \mu(\mathrm{k}) \mathrm{k}}{\mu(\mathrm{k})+\mathrm{f}}\left\{1-\mathrm{e}^{-[\mu(\mathrm{k})+\mathrm{f}] \mathrm{t}}\right\}
$$

Equation 4 can be rearranged to yield equation 5:

$$
\mathrm{C}(\mathrm{k})=\frac{\mathrm{R}(\mathrm{k})\{\mu(\mathrm{k})+\mathrm{f}\}}{\mathrm{N} \mu(\mathrm{k}) \mathrm{k}\left\{1-\mathrm{e}^{-[\mu(\mathrm{k})+\mathrm{f}] \mathrm{t}}\right\}}
$$

Using measured responses and known values of $\mu(\mathrm{k})$ and $\mathrm{f}, \mathrm{C}(\mathrm{k})$ can be determined from equation 5.

If $\mathrm{f}=0$, equation 5 reduces to:

$$
\mathrm{C}(\mathrm{k})=\frac{\mathrm{R}(\mathrm{k})}{\mathrm{Nk}\left\{1-\mathrm{e}^{-\mu(\mathrm{k}) t}\right\}}
$$

Thus it can be seen that $\mathrm{C}(\mathrm{k})$ is the ratio of the response of the TLD to the energy deposited in the TLD only when $\mathrm{f}=0$.

If the detector is read out with the irradiated side directed away from the PM tube:

$$
\mathrm{dR}^{\prime}(\mathrm{k})=\mathrm{C}^{\prime}(\mathrm{k}) \mathrm{N} \mu(\mathrm{k}) \mathrm{ke}^{-[x \mu(\mathrm{k})-\mathrm{f}(\mathrm{t}-\mathrm{x})]} \mathrm{dx}
$$

Integration of equation 7) over the thickness of the TLD results in:

$$
R^{\prime}(k)=\frac{C^{\prime} N \mu(k) k e^{-f t}\left\{1-e^{-[\mu(k)-f] t}\right\}}{\mu(k)-f}
$$

In the following analysis it will be assumed that $\mathrm{C}$ and $\mathrm{C}^{\prime}$ are the same. It would be reasonable to assume that $\varepsilon$ is the same in both cases, but it has to be verified experimentally that $\eta$ is not affected by possibly different temperature gradients inside the TLD when read with either side facing the planchet in the reader. 
Taking the ratio between the two responses we obtain:

$$
\frac{R^{\prime}(k)}{R(k)}=\frac{e^{-f t}\left\{1-e^{-[\mu(k)-f] t}\right\}\{\mu(k)+f\}}{\left\{1-e^{-[\mu(k)+f] t}\right\}\{\mu(k)-f\}}
$$

The light attenuation coefficient $f$ can be determined by solving equation 9) numerically, all other parameters being known. In addition $\mathrm{f}$ and $\mu(\mathrm{k})$ can be determined experimentally. The coefficient $\mu(\mathrm{k})$ can be determined experimentally by irradiating a stack of TLDs and reading out each individual TLD. The slope of the response vs. TLD depth, on a semi-log plot is equal to $\mu(\mathrm{k})$. The coefficient $\mathrm{f}$ can be obtained by irradiating several TLDs independently (to the same kerma) and then reading out the irradiated TLDs with varying numbers (0-5) of control TLDs placed on top of each irradiated TLD. The slope of the response vs control TLD thickness on a semi-log plot is $\mathrm{f}$. The latter should be independent of photon energy.

\section{EXPERIMENTAL CONDITIONS AND PROCEDURE}

The $0.04 \mathrm{~cm}$-thick MCP-N and MTS-N TLDs, are solid circular sintered pellets of diameter $=0.45 \mathrm{~cm}$. Experiments were performed at the SSRL beam line 1-5 using synchrotron radiation from the $3 \mathrm{GeV}$ electron storage ring SPEAR. The experimental layout and procedure are described in detail in References 1 and 2. The beam size at the sample position was about $0.14 \mathrm{~cm} \times 0.14 \mathrm{~cm}$. The monochromator was set at various energies ranging from 6 to $30 \mathrm{keV}$. The TLDs were mounted in specially designed sample holders. The temperature, pressure and ionization chamber integrated currents were noted at each irradiation. The ionization chamber readings were converted to air kerma and corrected for 
attenuation in the nitrogen and air paths to obtain the kerma in air at the sample position. At each energy (6 - $30 \mathrm{keV}), 6$ TLDs were exposed to air kermas ranging from 0.1 to $0.2 \mathrm{~Gy}$ with the front (numbered) side facing the beam. The numbers were inscribed lightly in pencil on one corner of the TLD, away from the central area of beam irradiation.. For energies between 6 and $16 \mathrm{keV}, 12$ TLDs were also exposed at each energy, to air kermas ranging from 0.01 to $0.03 \mathrm{~Gy}, 6$ with the front side facing the beam and 6 with the front side directed away from the beam. All 12 TLDs were read with the front side facing the PM tube. Note, that this is equivalent to irradiating all 12 TLDs from the front side and reading 6 with the front side facing the PM tube and 6 with the front side directed away from the PM tube. For the light attenuation studies 6 TLDs were exposed at 7, 8 and $10 \mathrm{keV}$. For the energy attenuation studies, 6 stacks of TLDs, each stack containing 6 TLDs were exposed at 7, 8 and $10 \mathrm{keV}$.

The TLDs were read out at the Institute of Nuclear Physics using an RA '94 reader (made by Mikrolab, Krakow, Poland) equipped with a photomultiplier tube (EMI 9789QB) with a bialkali photocathode and BG-12 optical filter. The pre-readout annealing consists of heating the dosemeters at $100^{\circ} \mathrm{C}$ for 10 minutes. The readout cycle consists of a linear ramp at $5^{\circ} \mathrm{C} / \mathrm{s}$. The maximum temperature is typically $350^{\circ} \mathrm{C}$ for MTS-N and $280^{\circ} \mathrm{C}$ for MCP-N. The annealing cycle is as follows: MTS-N - $400^{\circ} \mathrm{C}$ for 1 hour and $100^{\circ} \mathrm{C}$ for 2 hours and MCP-N $240^{\circ} \mathrm{C}$ for $10 \mathrm{~min}$. followed by fast cooling on an aluminum plate. All responses were normalized to $1 \mathrm{~Gy}$. 


\section{RESULTS AND DISCUSSION}

Figure 1 shows the responses relative to ${ }^{137} \mathrm{Cs}$ of MTS-N and MCP-N TLDs as a function of photon energy. The average relative responses and the standard deviations of the average are shown. The error bars only include the variation in the responses. In some cases the error bars are smaller than the size of the symbols and therefore not visible. The error of the kerma values is less than $4 \%$. The relative response of MTS-N increases from 0.4 to 1.4 between 6 and $30 \mathrm{keV}$ and that of MCP-N increases from 0.2 to 1.2 between 6 and $26 \mathrm{keV}$. Bilski et. al have reported a relative response of 1.1 at $30 \mathrm{keV}$ for $0.065 \mathrm{~cm}$-thick MCP-N TLS [3]. The marked decrease in response with decreasing photon energy is consistent with the fact that TL efficiency of MCP-N decreases strongly with increasing ionization density. No differences in the shape of the glow curves were observed for the photon energy range of 6 to $30 \mathrm{keV}$, for both types of TLDs.

For both TLD types the difference between the front and back irradiations was within the variability between the individual dosemeters [2]. Hence we were unable to determine $\mathrm{f}$ using equation 9. The differences in response between front and back irradiations may be more significant in thicker TLDs.

Tables 1 and 2 show the experimentally determined light attenuation coefficients and effective energy attenuation coefficients with their associated errors of fit. As expected, $f$ is independent of photon energy. A value of $\mathrm{f}=18.8 \mathrm{~cm}^{-1}$ for MCP-N, was measured by Bilski et al. in 1996 by comparing the TL signals of $5.5 \mathrm{MeV}$ alpha-irradiated detectors read out with the irradiated side facing the PM tube, and facing the planchet [4]. The method of measurement is described in reference 5. Since $5.5 \mathrm{MeV}$ alpha particles have a very short range in the TLD, it can be assumed that TL light originates only from the surface of the 
detector as a point source. It is important to note that the synchrotron radiation is a narrow $\left(1.96 \mathrm{~mm}^{2}\right)$ parallel collimated beam and irradiates only one eighth of the area of the TLD. At these low energies most of the photon scattering is in the forward direction, so the light emitting centers in the TLD are limited to a narrow area, effectively presenting a point source. The light produced is more nearly parallel than the light produced by the non-parallel alpha particles. Hence one would expect the value of $f$ obtained with the alpha particles to be higher than that obtained with the synchrotron radiation. However, there are some errors associated with these measurements. The determination of $\mathrm{f}$ inherently assumes a narrow beam geometry which would only be partially achieved by most TLD readers. We have also assumed that there is no reflection of light from the planchet. This is rather a simplistic view but measurements made by Olko et al (6) indicate a reflectivity of 0.25 from the planchet for $0.1 \mathrm{~mm}$ thin MTS-N detectors. Assuming zero reflectivity changes the self absorption factor, $\left(1-\mathrm{e}^{-\mathrm{fx}}\right) / \mathrm{f}$, by less than $2 \%$.

The calculated values of $\mu(\mathrm{k})$ in Table 2 were determined by Bilski using published cross sections. There are differences of up to $9 \%$ between the experimental and calculated values.

Figure 2 shows the relative TLD efficiency $\mathrm{C}(\mathrm{k}) / \mathrm{C}\left({ }^{137} \mathrm{Cs}\right)$ as a function of photon energy. The average values and the standard deviation of the average are shown. Also shown are the relative efficiencies for $0.072 \mathrm{~cm}$-thick MCP-N TLDs (Bilski et al) with $\mathrm{f}=10.5 \mathrm{~cm}^{-1}$ measured for narrow x-ray spectra [3]. The relative efficiency was determined in the following way. The number of photons $\mathrm{N}$ was determined using known values of air kerma. $\mathrm{C}(\mathrm{k})$ and $\mathrm{C}\left({ }^{137} \mathrm{Cs}\right)$ were determined from equation 6 by using measured values of $\mathrm{f}$ and calculated values of $\mu(\mathrm{k})$ and $\mathrm{N}$. The relative efficiency for MTS-N apparently goes through a peak between 6 and $10 \mathrm{keV}$, and then increases thereafter. Between 6 and $26 \mathrm{keV}$, the relative efficiencies of 
MTS-N and MCP-N increase by factors of 2 and 3, respectively. Bilski et. al have established an empirical relationship between the efficiency and the mean lineal energy that can be used to predict the TL response of MCP-N for photons and electrons [3]. According to Olko, the marked decrease of efficiency for weakly ionizing radiation can be explained by the saturation of TL response in a small (24 $\mu \mathrm{m}$ diameter) sensitive site in MCP-N [7].

\section{CONCLUSIONS}

The need for low-energy $\mathrm{x}$-ray dosemeters has increased because of the increasing number of synchrotron radiation facilities being built around the world. Responses of $0.04 \mathrm{~cm}$-thick MCP-N and MTS-N TLDs were determined using synchrotron radiation. Relative to ${ }^{137} \mathrm{Cs}$ gamma rays, the response of MTS-N (0.04 cm thick) increased from 0.04 to .14 between 6 and $30 \mathrm{keV}$ and that of MCP-N ( $0.04 \mathrm{~cm}$ thick) increased from 0.02 to 0.12 between 6 and 26 $\mathrm{keV}$.

The light attenuation coefficient $f$, and effective energy attenuation coefficient $\mu(\mathrm{k})$, were determined experimentally. Synchrotron radiation is more suited for such measurements because the beam is narrow and collimated. Efforts to determine $\mathrm{f}$ from the mathematical model for the $0.04 \mathrm{~cm}$-thick TLDs proved to be unsuccessful because the differences in response between irradiating the TLDs from the front and back were within the variability between the TLDs. The mathematical model for TLD response was used to determine quantities such as overall TLD efficiency and efficiency relative to ${ }^{137} \mathrm{Cs}$. Between 6 and 26 $\mathrm{keV}$, relative efficiencies for MTS-N and MCP-N increase by factors of 2 and 3, respectively. 


\section{ACKNOWLEDGMENTS}

The authors acknowledge Henry Bellamy, Ron Seefred and SSRL Experimental Support Group for their assistance. Gratitude is also expressed to Sherry Oppenheim and the SLAC Technical

Publications Department for their help in preparing this manuscript. Work supported by Department of Energy contract DE-AC03-76SF00515. Work supported in part by Grant No. 4 P05D 03013 from the Polish State Committee for Scientific Research.

\section{REFERENCES}

1. Ipe, N. E., Bellamy, H., Flood, J. R., Kase, K. R., Velbeck, K. J., and Tawil, R., Low-Energy X-ray Dosimetry Studies (7 to $17.5 \mathrm{keV}$ ) with Synchrotron Radiation, in Proceedings of the 11th International Conference on Solid State Dosimetry, 1995, pp. 69-74.

2. Ipe, N.E., Chatterji, S., Fasso', A., Kase, K.R., Seefred, R., Olko, P., Bilski, P., and Soares, C., LowEnergy X-ray Dosimetry Studies (6 to $16 \mathrm{keV}$ ) at SSRL Beam Line 1-5, in the Proceedings of Synchrotron Radiation Insrtrumentation, $10^{\text {th }}$ U.S. National Conference, Cornell University, Ithaca, New York, June 17-20, 1997 [AIP Conference Proceedings 417].

3. Olko, P., Bilski, P., Ryba E., and Niewiadomski T., Microdosimetric Interpretation of the Anomalous Photon Energy Response of Ultra-Sensitive LiF:Mg, Cu, P TL Dosimeters, Radiat. Prot. Dosim., 47, 31-35 (1993).

4. Private Communication, Bilski, $\mathrm{P}$

5. Bilski, P., Olko, P., Burgkhardt, B., Piesch, P., and Waligorski, M. P. R., Thermoluminescence Efficiency of LiF:Mg,Cu,P (MCP-N) Detectors to Photons, Beta Electrons, Alpha Particles and Thermal Neutrons, Radiat. Prot. Dosim., 55, 31-38 (1994).

6. Private Communication, Olko, P.

7. Olko, P., Microdosimetric Interpretation of Thermoluminescence Efficiency of LiF:Mg, Cu, P (MCPN) Detectors for Weakly and Densely Ionizing Radiations, Radiat. Prot. Dosim, 65, 151-158 (1990). 
Fig 1 Response of TLDs Relative to ${ }^{137} \mathrm{Cs}$ as a Function of Photon Energy

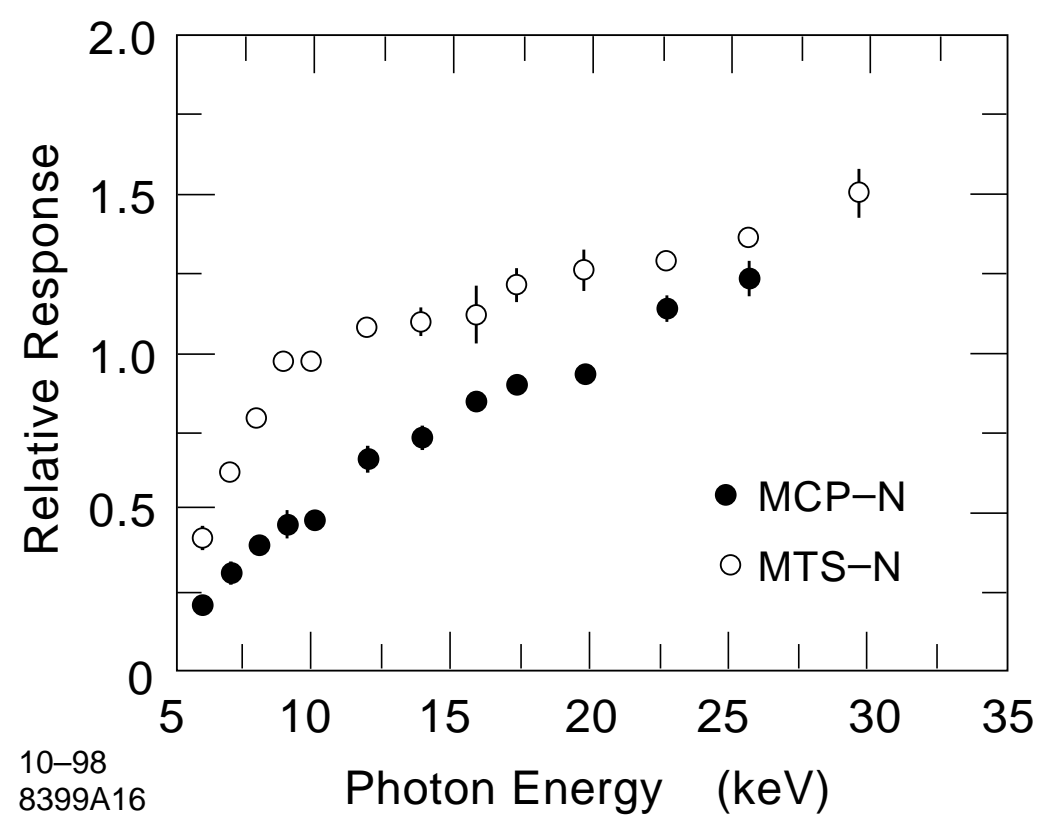

Fig 2 TLD Efficiency Relative to ${ }^{137} \mathrm{Cs}$ as a Function of Photon Energy

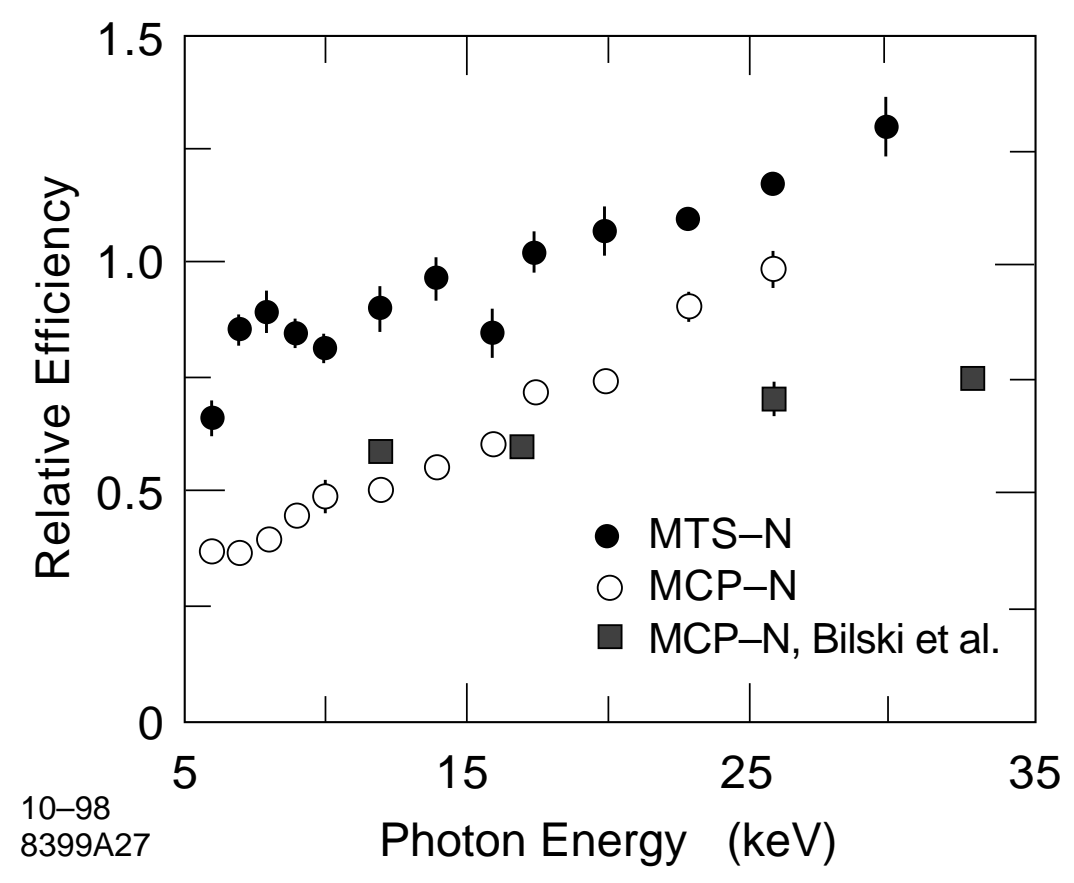


Table 1: Light Attenuation Coefficient as a Function of Photon Energy

\begin{tabular}{|c|c|c|}
\hline & \multicolumn{2}{|c|}{ f $\left(\mathrm{cm}^{-1}\right)$} \\
\hline $\begin{array}{c}\text { Energy } \\
(\text { kev })\end{array}$ & MTS-N & MCP-N \\
\hline 7 & $15.62 \pm 0.06$ & $17.20 \pm 0.1$ \\
\hline 8 & $15.78 \pm 0.06$ & $17.24 \pm 0.1$ \\
\hline 10 & $15.48 \pm 0.06$ & \\
\hline
\end{tabular}

Table 2: Effective Energy Attenuation Coefficient as a Function of Photon Energy

\begin{tabular}{|c|c|c|c|c|}
\hline \multirow{2}{*}{} & \multicolumn{4}{|c|}{$\mu(\mathrm{k})\left(\mathrm{cm}^{-1}\right)$} \\
\cline { 2 - 5 } & \multicolumn{2}{|c|}{ MTS-N } & \multicolumn{2}{c|}{ MCP-N } \\
\hline $\begin{array}{c}\text { Energy } \\
(\mathrm{keV})\end{array}$ & Experimental & Calculated & Experimental & Calculated \\
\hline 7 & $37.24 \pm 0.06$ & 41.06 & & 44.69 \\
\hline 8 & $29.89 \pm 0.04$ & 27.36 & & 29.87 \\
\hline 10 & $14.25 \pm 0.03$ & 13.92 & $12.13 \pm 0.005$ & 15.64 \\
\hline
\end{tabular}

